\title{
The hidden dangers of supplements: A case of substance-induced psychosis
}

\section{Briana Tillman, DO, IBCLC}

Y ou are what you eat," my mother always said, and structured our dinner plates according to the USDA food pyramid. We dutifully consumed leafy greens, and prior to medical school I invested time and money into healthy diet choices. I drank green smoothies, pureed baby food for my children, read up on the $\mathrm{pH}$ balancing diet, grew sprouts on windowsills, bought organic.

With the stressors and time constraints of managing medical school and a family, nutrition tumbled down the ladder of priorities until eventually my family was subsisting on chicken nuggets, pizza, and peanut butter. Intern year has only added the occasional candy bar from the doctors' lounge. I experienced a vague sense of loss for something I had once valued, but simultaneously felt dismissive of trendy topics such as omega-3 fatty acids and antioxidants in the face of myocardial infarctions and liver failure. A biochemistry professor once scoffed at "the laypeople's obsession with toxins," and nutrition received zero attention in our medical school curriculum or board exams.

However, a clinical experience on the inpatient psychiatric unit made me reevaluate the importance nutrition should have in both our personal lives and the practice of medicine. This is the case of an otherwise healthy young man with no psychiatric history who suffered a psychotic break after ingesting an excess of a supplement he purchased online with the purpose of improving his performance at a highstress job.

\section{CASE REPORT}

Mr. K, a 28-year-old computer programmer, was voluntarily admitted to the inpatient psychiatry unit for paranoia and persecutory delusions along with auditory hallucinations. His father reported that Mr. K had been behaving erratically for several days prior to admission and was subsequently found wandering in the street.

On admission, Mr. $\mathrm{K}$ was not oriented to place or situation. He was unkempt and guarded, and claimed people were following him. His urine toxicology screen and blood alcohol levels were negative.

While hospitalized, Mr. K was hyperverbal and delusional. He related that at work he had been developing programs to make slaves in the computer, "algorithms for orchestration," and that he was uncomfortable with the ethical implications. He eventually endorsed having purchased the supplement phenylethylamine (PEA) to improve his focus, and ingesting "two substantial scoops of the crystalline substance."

We did not initiate any psychiatric medications. On the third day of his hospitalization, Mr. K was alert, oriented, euthymic, relaxed, and had a full range of affect; upon discharge we advised him to discard the PEA and avoid stimulants. He complied, quit his high-stress

LET YOUR VOICE BE HEARD

CURRENT PsYCHIATRY invites psychiatry residents to share their views on professional or clinical topics for publication in Residents' Voices. E-mail jbauer@mdedge.com for author guidelines.

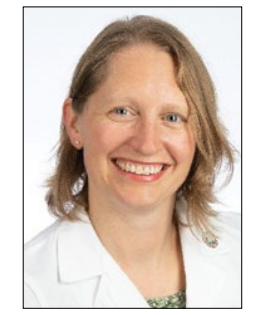

Dr. Tillman is a PGY-1 Psychiatry Resident, Department of Psychiatry, The Medical Center of Aurora, Aurora, Colorado.

\section{Disclosure}

The author reports no financial relationships with any companies whose products are mentioned in this article, or with manufacturers of competing products. 
Clinical Point

Phenylethylamine

acts as a natural

amphetamine and

may be a cause of

psychosis job, and had no subsequent psychotic symptoms in the 7 months since discharge.

\section{Dietary supplements carry risks}

According to the FDA, dietary supplements are regulated as food, but many have strong biologic effects or may even contain drugs. ${ }^{1}$ More than $18 \%$ of Americans use herbal or nutritional therapies as part of their health regimen. ${ }^{2}$ However, many over-the-counter remedies have been found to exhibit psychotropic effects, ${ }^{3}$ and many more are purported to impact mental and physical health with little to no scientific research into these claims or potential adverse effects.

Phenylethylamine is sold as a nutritional supplement and marketed for its purported beneficial effects on weight loss, mood, and focus. ${ }^{4}$ However, PEA is known to act as a natural amphetamine and to play a role in the development of neuropsychiatric disorders. ${ }^{5}$ It is an endogenous psychotogenic molecule that has been previously theorized as a cause for primary psychosis. ${ }^{6}$ Phenylethylamine interacts with the same receptor ligand that responds to amphetamine and related compounds (such as methamphetamine and 3,4-methylenedioxy-methamphetamine [MDMA]), the genetic coding for which is located in an area of DNA associated with schizophrenia: chromosome 6q23.2. While the mechanisms and details of these interactions remain poorly understood, this case of PEA-induced psychosis represents a glimpse into the potential psychoactive properties of this readily available nutritional supplement.

This patient's cautionary tale has given me pause regarding both my family's nutrition and the oft-neglected dietary portion of the social history. Also, several subsequent patient experiences hearken back to my mother's words regarding the importance of healthy eating. A patient with phenylketonuria presented with psychosis after running out of her formula and consuming junk food. Another patient with severely elevated blood glucose levels presented with confusion. I have come to realize that ingestion impacts presentation, or, in other words, you are what you eat.

\section{References}

1. US Food and Drug Administration. Dietary supplements. https://www.fda.gov/consumers/consumer-updates / dietary-supplements. Accessed December 11, 2019.

2. Tindle $H$, Davis $R$, Philips $R$, et al. Trends in use of complementary and alternative medicine by US adults: 19972002. Altern Ther Health Med. 2005;11(1):42-49.

3. Sarris J. Herbal medicines in the treatment of psychiatric disorders: 10-year updated review. Phytotherapy Research. 2018;32(7):1147-1162.

4. Irsfeld M, Spadafore M, Prüß BM. $\beta$-phenylethylamine, a small molecule with a large impact. WebmedCentral. 2013;4(9):4409.

5. Wolf M, Mosnaim A. Phenylethylamine in neuropsychiatric disorders. Gen Pharmacol. 1983;14(4):385-390.

6. Janssen P, Leysen J, Megens A, et al. Does phenylethylamine act as an endogenous amphetamine in some patients? In J Neuropsychopharmacol. 1999;2(3):229-240.

7. Zucchi R, Chiellini G, Scanlan TS, et al. Trace amine-associated receptors and their ligands. Br J Pharmacol. 2006;149(8):967-978. 